\title{
Avaliação do Perfil de Sensibilidade aos Antibióticos na Infeção Urinária da Comunidade
}

\author{
Evaluation of the Antimicrobial Susceptibility of Community-Acquired Urinary \\ Tract Infection
}

Rui PASSADOURO ${ }^{1}$, Raquel FONSECA ${ }^{2}$, Felícia FIGUEIREDO ${ }^{3}$, Andreia LOPES $^{4}$, Cristina FERNANDES ${ }^{5}$

Acta Med Port 2014 Nov-Dec;27(6):737-742

RESUMO

Introdução: As infeções do trato urinário, depois das infeções respiratórias, são as mais comuns na comunidade. O conhecimento sobre a prevalência das estirpes microbianas e a sua suscetibilidade aos antibióticos é fundamental para instituir uma terapêutica empírica eficaz. O objetivo deste estudo foi determinar os padrões de suscetibilidade aos antibióticos das estirpes bacterianas isoladas em uroculturas positivas efetuadas em doentes da região centro de Portugal.

Material e Métodos: Procedemos a uma análise documental dos 6008 resultados de uroculturas, a disponibilizar aos médicos no ano de 2013, a maioria das quais executadas através do sistema automatizado VITEK 2 da bioMérieux. A análise dos dados foi efetuada através do SPSS versão 21 .

Resultados: A maioria (80\%) das 6008 uroculturas positivas foi efetuada no sexo feminino. A Escherichia coli foi a bactéria mais prevalente na amostra $(65,9 \%)$, seguida pela Klebsiella spp (12\%). A Nitrofurantoína apresentou elevada eficácia (96\%) para as estirpes de E. coli, bem como a Fosfomicina (96,6\%). A Amoxicilina-Ácido Clavulânico apresentou um nível de eficácia de apenas $81,1 \%$, para o mesmo gérmen. As quinolonas apresentaram eficácia para $78 \%$ das estirpes de $E$. coli, sendo inferior à registada para a Fosfomicina e para a Nitrofurantoína.

Discussão: O presente estudo revelou que a $E$. coli foi o agente patogénico predominante nas infeções do trato urinário da comunidade (65,9\%) apresentando percentagens de sensibilidade elevadas à Fosfomicina (96,6\%) e à Nitrofurantoína (96\%).

Conclusão: Recomenda-se a monitorização do perfil sensibilidade dos microrganismos aos antibióticos, de modo a otimizar a terapêutica empírica das ITU.

Palavra-chave: Infeções Urinárias; Resistência aos Antibióticos; Agentes Bacterianos; Infeções Comunitárias Adquiridas.

\section{ABSTRACT}

Introduction: The urinary tract infections, after respiratory infections, are the most common in the community. The knowledge about the prevalence of microbial strains and their antibiotic susceptibility is crucial to establish an effective empirical therapy. The aim of this study was to determine the antibiotic susceptibility patterns of bacterial strains isolated from positive urine cultures performed in patients from the central region of Portugal.

Material and Methods: We carried out a documental analysis of 6008 urine bacteriological exams, to be made available to physicians, most of which run through the automated system VITEK 2, bioMérieux. The majority ( $80 \%)$ of the urine bacteriological exams were from female. Escherichia coli was the most prevalent bacterial pathogen $(65.9 \%)$, followed by Klebsiella spp (12\%).

Results: Nitrofurantoin showed high levels of activity (96\%) for Escherichia coli, as well as Fosfomycin (96.6\%). Amoxicillin-clavulanic acid presents an activity level of only $81.1 \%$ for the same germ. Quinolones exhibit efficacy to only $78 \%$ of the strains of Escherichia coli, below the Fosfomycin and Nitrofurantoin. Nitrofurantoin showed high levels of activity (96\%) for E. coli as well as Fosfomycin (96.6\%). Amoxicillin-Clavulanic Acid presents a level of activity of only $81.1 \%$ for the same germ. The quinolones have a efficacy for only $78 \%$ of strains of $E$. coli, lower than Fosfomycin.

Discussion: Escherichia Coli was the most prevalent uropathogen (65.9\%). High efficacy against this pathogenic agent was found for Fosfomycin (96.6\%) and Nitrofurantoin (96\%).

Conclusion: Further antimicrobial surveillance studies should be developed, in order to formulate local empirical therapy recommendations for optimized therapeutical choices.

Keywords: Urinary Tract Infections; Drug Resistance, Bacterial; Anti-Bacterial Agents; Community-Acquired Infections.

\section{INTRODUÇÃO}

A resistência aos antibióticos $(R A)$ é um fenómeno natural que representa uma séria ameaça à saúde pública, levando ao aumento dos custos com os cuidados de saúde, ao insucesso terapêutico e, por vezes, à morte. ${ }^{1} \mathrm{~A}$ sua frequência crescente representa um problema complexo resultante de múltiplos fatores, entre os quais se encontra o uso indiscriminado dos antibióticos. Trata-se de um problema grave, à escala mundial, que afeta tanto os países desenvolvidos como os em desenvolvimento. ${ }^{2}$

A progressão da RA potencia o aparecimento de infeções multirresistentes, de tratamento difícil e oneroso e, por ser irreversível, ou de reversão muito lenta, torna-se particularmente preocupante.

A RA foi considerada, pela Organização Mundial de Saúde (OMS) um problema prioritário, pelo que, desde 2001, instituíram medidas globais para o seu controlo,

1. Unidade de Saúde Pública. Agrupamento de Centros de Saúde do Pinhal Litoral. Leiria. Portugal.

2. Departamento de Neurociências Clínicas e Saúde Mental. Faculdade de Medicina. Universidade do Porto. Porto. Portugal.

3. Faculdade de Psicologia e Ciências da Educação. Universidade de Coimbra. Coimbra. Portugal.

4. Núcleo de Planeamento. Agrupamento de Centros de Saúde do Pinhal Litoral. Leiria. Portugal.

5. Comissão de Controlo de Infeção. Agrupamento de Centros de Saúde do Pinhal Litoral. Leiria. Portugal

Recebido: 18 de Março de 2014 - Aceite: 29 de Julho de 2014 | Copyright @ Ordem dos Médicos 2014 
salientando-se a vigilância da resistência, a educação dos prescritores, dos profissionais de saúde e do grande público e a regulamentação da promoção de antibióticos pela indústria farmacêutica. ${ }^{2}$

$\mathrm{Na}$ Europa, o consumo de antibióticos em doentes da comunidade, apresenta uma grande variação entre os diferentes países, com menor consumo no norte, moderado no leste e alto no sul. ${ }^{3} \mathrm{O}$ consumo é avaliado em dose diária definida por 1000 habitantes por dia (DID). ${ }^{4} \mathrm{Em} \mathrm{2002,}$ a França tinha o maior consumo (32,2 DID) e a Holanda o menor (10,0 DID). Portugal ocupava a terceira posição, com cerca de 27 DID. $^{3}$ Entre 2000 e 2009, o consumo de antibióticos, no continente português passou de 24,12 para 22,03 DID. ${ }^{5}$

O consumo de quinolonas em doentes da comunidade, em 2002, variava entre 3,76 DID na Itália, 3,6 em Portugal e 0,17 na Dinamarca. ${ }^{3}$ No entanto, o consumo de tetraciclinas, cefalosporinas, sulfonamidas e quinolonas diminuiu entre 2000 a 2009, com um aumento do uso de penicilinas em associação com inibidor das beta-lactamases. ${ }^{5}$ Segundo o mesmo estudo, na região centro de Portugal, o consumo de antibióticos, em 2009, era de 22,56 DID.

As infeções do trato urinário (ITU), depois das infeções respiratórias, são as mais frequentes na comunidade, apresentando maior incidência no sexo feminino. ${ }^{6}$

As bactérias são os principais agentes microbianos responsáveis pelas ITU. Os microrganismos mais prevalentes são as bactérias aeróbias gram-negativas, sendo a Escherichia coli (E. coli) a responsável por cerca de 75 a $90 \%$ das infeções agudas do trato urinário, seguindo-se Staphylococcus, Proteus, Klebsiella pneumoniae e Pseudomonas. A E. coli é também o principal agente infecioso responsável pelas pielonefrites complicadas e não complicadas. ${ }^{7}$

Num estudo com dados referentes a uroculturas de $1997^{6}$ verificou-se que a $E$. coli esteve implicada em $76,6 \%$ das ITU, o Proteus mirabilis (P. mirabilis) em $15,6 \%$ e a Klebsiella pneumoniae em $3,7 \%$. O mesmo autor, em 2006 , identificou como mais frequentes a $E$. coli $(64,0 \%)$, seguida do $P$. mirabilis $(9,3 \%)$ e do Enterococcus $(7,4 \%)$. Noutro estudo, Martins ${ }^{8}$ identificou a $E$. coli em $73,3 \%$ das ITU, o P. mirabilis em 7,6\%, a Klebsiella pneumoniae em $10 \%$, o Enterococcus faecalis em $3,5 \%$ e a Pseudomonas aeruginosa em 3,1\%. Num estudo de âmbito hospitalar, ${ }^{9}$ com 572 amostras, 144 de internamento e 428 de doentes externos, a prevalência dos agentes microbianos foi de $68,8 \%$ para a Escherichia coli, $7,9 \%$ para a Klebsiella pneumoniae, 6,1\% para a Pseudomonas aeruginosa e 5,2\% para o Proteus mirabilis. Linhares et al, ${ }^{10}$ num estudo com 18797 uroculturas positivas, identificaram a E.Coli em $64,5 \%$ das amostras, o Staphylococcus aureus em 6,0\%, o P. mirabilis em 4.7\%, a Klebsiella spp em 4,3\%, o Enterococcus faecalis 3,6\%, o Proteus vulgaris em $2,7 \%$ e a Pseudomonas aeruginosa em 2,4\%.

Num estudo desenvolvido em 2009, ${ }^{6}$ que envolveu 2676 uroculturas, verificou-se que $37,2 \%$ das estirpes de $E$. coli eram resistentes à Tobramicina, $24,7 \%$ à Norfloxacina, $20,7 \%$ à Ciprofloxacina e 12,7\% à Amoxicilina-Ácido Clavulânico. O P. mirabilis apresentava $21,9 \%$ de estirpes resis- tentes à Ampicilina, 15,6\% ao Trimetoprim-Sulfametoxazol, $6,1 \%$, à Amoxicilina-Ácido Clavulânico e $3 \%$ à Nitrofurantoína. A Klebsiella apresentava uma resistência de 12,5\% à Cefalexina, $0 \%$ à Cefuroxima, 38,5\% à Nitrofurantoína e $15,6 \%$ ao Trimetoprim-Sulfametoxazol. Linhares et $\mathrm{al}^{10}$ encontrou 3,0 \% das estirpes de E. coli resistentes à Tobramicina, $14,2 \%$ à Norfloxacina, $13,9 \%$ à Ciprofloxacina, $7,5 \%$ à Amoxicilina-Ácido Clavulânico e $6 \%$ à Nitrofurantoína.

A resistência dos microrganismos aos antibióticos aumenta com o consumo dos mesmos, verificando-se uma menor taxa de resistência nos países do norte da Europa, onde o consumo é menor. ${ }^{3}$

Estima-se que entre 50 a $70 \%$ das mulheres têm uma ITU durante a vida e que 20 a $30 \%$ têm episódios recorrentes, havendo indicação para tratamento antes de se conhecer o antibiograma. ${ }^{11} \mathrm{~A}$ antibioterapia empírica, para tratamento da ITU, associa-se a taxas de erradicação microbiológica iguais ou superiores a $90 \%,{ }^{12}$ quando a decisão de prescrição do antibiótico se fundamenta no conhecimento dos principais agentes microbianos envolvidos e se conhece o seu perfil de sensibilidade.

Assim, é fundamental a monitorização do perfil de sensibilidade dos antibióticos de forma a orientar a terapêutica antimicrobiana empírica. ${ }^{13} \mathrm{~A}$ escassez de estudos justifica a realização de uma investigação epidemiológica sobre a resistência aos antibióticos dos agentes infeciosos mais frequentes, nas ITU da comunidade.

A presente investigação tem como objetivo determinar o perfil de sensibilidade aos antimicrobianos dos principais agentes infeciosos das ITU adquiridas na comunidade geográfica do ACES Pinhal Litoral (NUTS III).

\section{MATERIAL E MÉTODOS}

Trata-se de um estudo retrospetivo, descritivo, no qual foram observados os resultados laboratoriais das uroculturas efetuadas no ano de 2013, pelos laboratórios de maior implantação na área geográfica do Pinhal Litoral (NUTS III). A amostra é constituída por 6008 uroculturas positivas (> 100000 unidades formadores de colónias - UFC). As identificações das estirpes e os antibiogramas foram executados através do sistema automatizado VITEK 2, da bioMérieux, tendo sido utilizadas as diversas cartas adequadas. Foram ainda utilizados o sistema mini API, da bioMérieux, e o método de difusão em disco de Kirby \& Bauer, em 10\% das amostras.

De acordo com a metodologia do Clinical and Laboratory Standards Institute, ${ }^{14}$ os resultados foram classificados em sensível (S), intermédio (I) e resistente (R). Posteriormente, as amostras com resultado 'intermédio' foram recodificadas como resistentes. Foram também colhidos dados relativos ao sexo e à idade dos doentes referentes a cada urocultura.

A sensibilidade aos antibióticos foi avaliada para os gérmenes cujo número absoluto de isolados na amostragem total foi superior a 150. Foram cinco os microrganismos que cumpriram este critério (Tabela 1).

O tratamento estatístico dos dados foi efetuado através 
do programa Statistical Package for the Social Sciences (SPSS), versão 21 para Windows.

\section{RESULTADOS}

A amostra é constituída por 6008 uroculturas positivas. O sexo feminino constitui $80 \%$ da amostra, com 4911 uroculturas positivas.

A média de idades foi de 62,8 anos, $( \pm 20,7)$, com um mínimo de seis meses e um máximo de 107 anos.

A distribuição das ITU por classe etária revela uma maior prevalência acima dos 75 anos (34,9\%), seguida dos 56 a 75 anos (30\%), representando o grupo etário superior a 55 anos, $65 \%$ da amostra. O grupo etário com menos de 16 anos representa 1,6\% da amostra (Fig. 1).

A estirpe predominante foi a $E$. coli $(65,9 \%)$, seguida da Klebsiella pneumoniae (12\%), P. mirabilis (7\%), E. faecalis (4,8\%), Pseudomonas aeruginosa (2,7\%), Morganella $(1,8 \%)$ e outras com $5,7 \%$. O Acinetobacter baumannii foi identificado em 11 amostras (0,4\%) (Tabela 1$)$.
Considerando a distribuição das três estirpes mais prevalentes, E. coli, Klebsiella pneumoniae e Proteus mirabilis, que representam $84,9 \%$ da amostra, verifica-se que a sua prevalência varia segundo o grupo etário.

A E. coli continua a ser a mais prevalente, representando $72,4 \%$ e $74,6 \%$ das estirpes nos grupos etários $16-35$ e $36-55$, respetivamente. Entre os indivíduos com mais de 75 anos está presente em $55,4 \%$ das amostras. A Klebsiella pneumoniae tem a prevalência de $16,3 \%$, no mesmo grupo etário.

O Proteus mirabilis, com a prevalência de $7 \%$, no total da amostra, apresenta no grupo etário $<16$ anos uma prevalência de 21,6\% (Tabela 2).

A sensibilidade aos antibióticos foi avaliada para os cinco gérmenes mais prevalentes, de acordo com os critérios estabelecidos. As estirpes de $E$. coli foram sensíveis em 96,6\% à Fosfomicina, 96,0\% à Nitrofurantoína, $93,0 \%$ à Gentamicina, $99,0 \%$ ao Imipenem, $96,1 \%$ à Amicacina, $94,9 \%$ à Ceftriaxona e $91,8 \%$ à Ceftazidima.

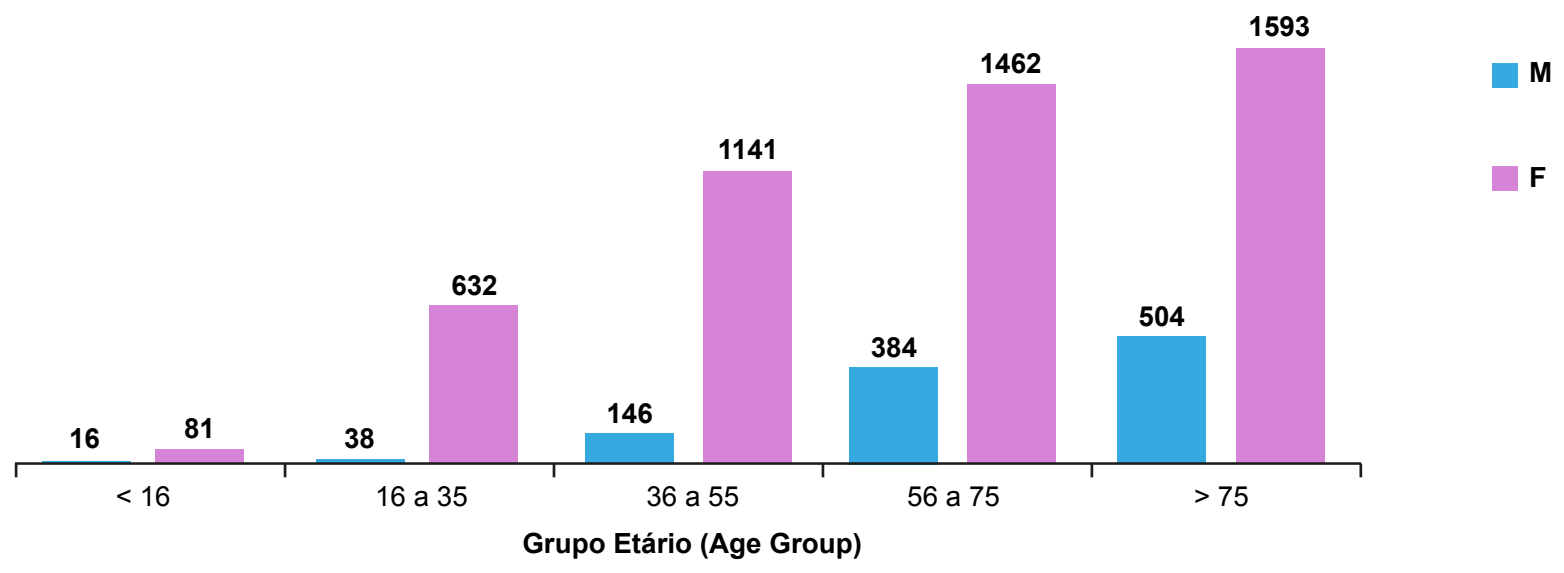

Figura 1 - Frequência das ITU por grupo etário

Tabela 1 - Prevalência das estirpes bacterianas

\begin{tabular}{|c|c|c|c|c|c|c|}
\hline \multirow[b]{2}{*}{ Organismo } & \multicolumn{2}{|c|}{ Masculino } & \multicolumn{2}{|c|}{ Feminino } & \multicolumn{2}{|c|}{ Total } \\
\hline & $n$ & $\%$ & $n$ & $\%$ & $n$ & $\%$ \\
\hline Escherichia coli & 494 & 12,5 & 3465 & 87,5 & 3962 & 65,9 \\
\hline Klebsiella pneumoniae & 165 & 22,9 & 554 & 77,1 & 719 & 12,0 \\
\hline Proteus mirabilis & 100 & 23,8 & 321 & 76,2 & 423 & 7,0 \\
\hline Enterococcus faecalis & 105 & 36,5 & 183 & 63,5 & 288 & 4,8 \\
\hline Pseudomonas aeruginosa & 77 & 47,2 & 86 & 52,8 & 163 & 2,7 \\
\hline Morganella & 47 & 44,3 & 59 & 55,7 & 106 & 1,8 \\
\hline Citrobacter & 26 & 27,1 & 70 & 72,9 & 96 & 1,6 \\
\hline Enterobacter & 15 & 17,4 & 71 & 82,6 & 86 & 1,4 \\
\hline Staphylococcus aureus & 24 & 32,4 & 50 & 67,6 & 74 & 1,2 \\
\hline Providencia stuartii & 16 & 35,6 & 29 & 64,4 & 45 & 0,7 \\
\hline Serratia marcescens & 12 & 50,0 & 12 & 50,0 & 24 & 0,4 \\
\hline Acinetobacter baumannii & 11 & 50,0 & 11 & 50,0 & 22 & 0,4 \\
\hline TOTAL & 1092 & 20 & 4911 & 80,0 & 6008 & 100,0 \\
\hline
\end{tabular}


Relativamente à Amoxicilina-Ácido Clavulânico e à Ciprofloxacina, a sensibilidade foi de $81,1 \%$ e $78,4 \%$, respetivamente (Tabela 3).

A Klebsiella pneumoniae apresenta uma percentagem de sensibilidade elevada à Amicacina $(95,7 \%)$ e Imipenem $(99,5 \%)$. Apresenta sensibilidade de $76,9 \%$ à Gentamicina e $75,8 \%$ à Ceftriaxona. $O$ Proteus apresenta uma percentagem de sensibilidade elevada à Ceftriaxona (96,8\%) ao Amoxicilina-Ácido Clavulânico $(87,7 \%)$ e à Cefuroxima $(87,2 \%)$. O Enterococcus faecalis apresenta $96 \%$ de sensibilidade à Nitrofurantoína, $79,3 \%$ à Ampicilina e $74,5 \%$ à Benzilpenicilina. A Pseudomonas apresenta $92,3 \%$ de sensibilidade à Amicacina, $86,5 \%$ à Gentamicina e $57,1 \%$ à $\mathrm{Ci}$ profloxacina. Em relação a Morganella, apresenta 94,2\% de sensibilidade à Amicacina e $71,5 \%$ à Ceftazidima (Tabela 3 ).

As estirpes de E. coli apresentam percentagem de sensibilidade elevada à Fosfomicina em todos os grupos etários, registando-se o valor mais baixo no grupo etário acima dos 75 anos (93\%) (Tabela 4). Não foi realizado o teste de sensibilidade para este antibiótico no primeiro trimestre de
2013.

A Cefuroxima apresenta eficácia para a $E$. coli em mais de $92,9 \%$ das estirpes até aos 55 anos, decrescendo para $88 \%$ e $79,4 \%$ nos grupos $56-75$ anos e $>75$ anos, respetivamente.

A Amoxicilina-Ácido Clavulânico apresenta atividade para $E$. coli em $84,8 \%$ das estirpes, no grupo etário < 16 anos, e $87 \%$ no grupo 16 a 35 anos. Depois dos 75 anos, a eficácia fixa-se nos $73,5 \%$ (Tabela 5).

A Nitrofurantoína apresenta altos níveis de atividade para a E. coli, sendo cerca de $97 \%$ das estirpes sensíveis até aos 75 anos. Depois dos 75 anos mantem-se eficaz em $92,4 \%$.

\section{DISCUSSÃO}

As uroculturas positivas são, na sua grande maioria $(80 \%)$, provenientes do sexo feminino, de forma concordante com outros estudos já realizados. ${ }^{7-9}$

As estirpes encontradas no nosso estudo são sobreponíveis às descritas na literatura, sobretudo para as três mais

Tabela 2 - Prevalência das estirpes bacterianas por grupo etário

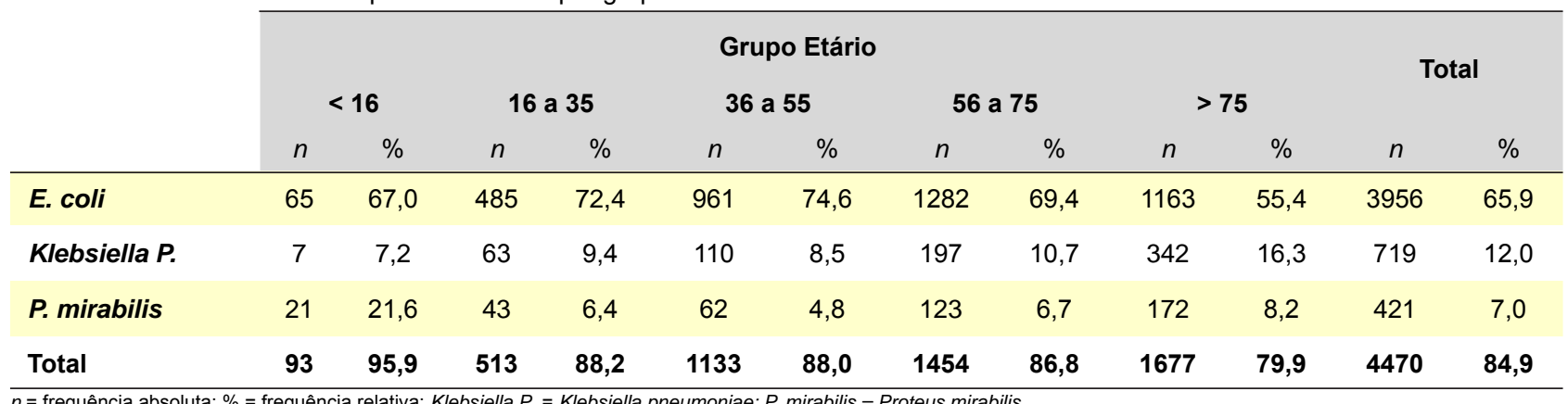

$n=$ frequência absoluta; \% = frequência relativa; Klebsiella $P$. = Klebsiella pneumoniae; $P$. mirabilis = Proteus mirabilis.

Tabela 3 - Perfil de sensibilidade aos antibióticos (\%)

\begin{tabular}{lcccccc}
\hline Antibiótico & E. coli & Klebsiella & Proteus & E. faecalis & Pseudomonas & Morganella \\
\hline Amicacina & 96,1 & 95,7 & 99,0 & $\mathrm{Nd}$ & 92,33 & 94,2 \\
Ampicilina & 62,5 & 20,4 & 68,5 & 79,3 & $\mathrm{Nd}$ & 1,0 \\
Amox-AcClav & 81,1 & 71,1 & 87,7 & 4,8 & 40 & 1,5 \\
Ceftazidima & 91,8 & 72,0 & 90,9 & $\mathrm{Nd}$ & 79,7 & 71,4 \\
Ciprofloxacina & 78,4 & 65,4 & 66,5 & $\mathrm{Nd}$ & 57,1 & 39 \\
Ceftriaxona & 94,9 & 75,8 & 96,8 & $\mathrm{Nd}$ & $\mathrm{Nd}$ & $\mathrm{Nd}$ \\
Cefuroxima & 86,1 & 65,5 & 87,2 & 7,2 & 20,0 & $\mathrm{Nd}$ \\
Cotrimoxazol & 75,5 & 66,4 & 60,1 & $\mathrm{Nd}$ & $\mathrm{Nd}$ & 35,9 \\
Fosfomicina & 96,6 & 59,8 & 81,4 & $\mathrm{Nd}$ & $\mathrm{Nd}$ & $\mathrm{Nd}$ \\
Gentamicina & 93,0 & 76,9 & 85,4 & $\mathrm{Nd}$ & 86,5 & 59,0 \\
Imipenem & 99,9 & 99,5 & 36,6 & 76,3 & 73,2 & 32 \\
Levofloxacina & 75,0 & 75,0 & $\mathrm{Nd}$ & $\mathrm{Nd}$ & $\mathrm{Nd}$ & $\mathrm{Nd}$ \\
Nitrofurantoína & 96,0 & $\mathrm{Nd}$ & $\mathrm{Nd}$ & 96,0 & $\mathrm{Nd}$ & $\mathrm{Nd}$ \\
Benzilpenicilina & $\mathrm{Nd}$ & $\mathrm{Nd}$ & $\mathrm{Nd}$ & 74,5 & $\mathrm{Nd}$ & $\mathrm{Nd}$ \\
Pip.Tazobactan & 96,8 & 81,1 & 91,2 & $\mathrm{Nd}$ & 62,7 & $\mathrm{Nd}$ \\
\hline
\end{tabular}


Tabela 4 - Perfil de sensibilidade da E. coli à Fosfomicina por grupo etário

\begin{tabular}{|c|c|c|c|c|c|c|c|c|c|c|c|c|c|}
\hline & & \multicolumn{10}{|c|}{ Grupo Etário } & \multirow{2}{*}{\multicolumn{2}{|c|}{ Total }} \\
\hline & & & & & & & & & & & & & \\
\hline & & \multicolumn{2}{|c|}{$<16$} & \multicolumn{2}{|c|}{16 a 35} & \multicolumn{2}{|c|}{36 a 55} & \multicolumn{2}{|c|}{56 a 75} & \multicolumn{2}{|c|}{$>75$} & \multirow[b]{2}{*}{$n$} & \multirow[b]{2}{*}{$\%$} \\
\hline & & $n$ & $\%$ & $n$ & $\%$ & $n$ & $\%$ & $n$ & $\%$ & $n$ & $\%$ & & \\
\hline \multirow{2}{*}{ Fosfomicina } & $\mathbf{R}$ & 0 & 0,0 & 5 & 1,5 & 11 & 1,6 & 23 & 2,6 & 55 & 6,6 & 94 & 3,4 \\
\hline & $\mathbf{S}$ & 44 & 100,0 & 334 & 98,5 & 668 & 98,4 & 859 & 97,4 & 784 & 93,4 & 2689 & 96,6 \\
\hline Total & & 44 & 100,0 & 339 & 100,0 & 679 & 100,0 & 882 & 100,0 & 839 & 100,0 & 2783 & 100,0 \\
\hline
\end{tabular}

$\mathrm{R}=$ Resistente; $\mathrm{S}=$ Sensível; $n=$ frequência absoluta; \% = frequência relativa.

Tabela 5 - Perfil de sensibilidade da E. coli a Amoxicilina-Ácido Clavulânico por grupo etário

\begin{tabular}{|c|c|c|c|c|c|c|c|c|c|c|c|c|c|}
\hline & & & & & & & & & & & & & \\
\hline & & \multicolumn{10}{|c|}{ Grupo Etário } & \multirow{3}{*}{\multicolumn{2}{|c|}{ Total }} \\
\hline & & & & & & & & & & & & & \\
\hline & & \multicolumn{2}{|c|}{$<16$} & \multicolumn{2}{|c|}{16 a 35} & \multicolumn{2}{|c|}{36 a 55} & \multicolumn{2}{|c|}{56 a 75} & \multicolumn{2}{|c|}{$>75$} & & \\
\hline & & $n$ & $\%$ & $n$ & $\%$ & $n$ & $\%$ & $n$ & $\%$ & $n$ & $\%$ & $n$ & $\%$ \\
\hline \multirow{2}{*}{$\begin{array}{l}\text { Amoxi- } \\
\text { Ac Clavulânico }\end{array}$} & $\mathbf{R}$ & 7 & 15,2 & 46 & 13,0 & 112 & 16,2 & 147 & 16,4 & 227 & 26,5 & 539 & 18,9 \\
\hline & $\mathbf{s}$ & 39 & 84,8 & 309 & 87,0 & 581 & 83,8 & 751 & 83,6 & 628 & 73,5 & 2308 & 81,1 \\
\hline \multicolumn{2}{|l|}{ Total } & 46 & 100 & 355 & 100 & 693 & 100 & 898 & 100 & 855 & 100 & 2847 & 100 \\
\hline
\end{tabular}

frequentes: E. coli; Klebsiella pneumoniae; e Proteus. ${ }^{6,8-10}$ No entanto, a prevalência de $E$. coli $(65,9 \%)$ é inferior à estimada nos referidos estudos, que se situa entre 75 e $90 \% .{ }^{7}$ Os indivíduos com mais de 75 anos, que representam $34,5 \%$ da nossa amostra, apresentam uma diminuição da prevalência desta estirpe $(55,4 \%)$. Entre os doentes internados, a prevalência de $E$. coli era inferior $(61,8 \%)$ à dos doentes externos $(70,6 \%),{ }^{9}$ salientando a importância da institucionalização como determinante da prevalência relativa dos patogéneos.

A Klebsiella pneumoniae foi encontrada em $12 \%$ do total de uroculturas, o que representa uma prevalência superior aos estudos já referidos, que variam entre $3,7 \%{ }^{6}$ e $10 \%{ }^{8}$ No grupo $>75$ anos a prevalência é de $16,3 \%$, acima do encontrada nos estudos consultados.

A antibioterapia empírica adequada para tratamento da ITU deve basear-se no conhecimento dos principais agentes microbianos envolvidos e no seu perfil de sensibilidade aos antibióticos. ${ }^{11}$ A E. coli apresentava percentagem de sensibilidade elevada à Fosfomicina (96,6\%) o que, de acordo com a Direção Geral de Saúde, ${ }^{12}$ permite a terapêutica empírica eficaz com este antibiótico. A sensibilidade das quinolonas, representadas pela Ciprofloxacina $(78,4 \%)$ e Levofloxacina (75\%), é semelhante à encontrada noutros estudos, ${ }^{6}$ sendo considerada baixa, o que poderá justificar-se pelo seu uso excessivo, figurando Portugal entre os países de maior consumo. ${ }^{3,15}$

A Klebsiella pneumoniae, que representava $12 \%$ das bactérias isoladas, apresenta baixa percentagem de sensibilidade para a Amoxicilina-Ácido Clavulânico $(71,1 \%)$, Cefuroxima (65,5\%) e Cotrimoxazol $(66,6 \%)$, o que está de acordo com um estudo prévio, efetuado em Portugal em
2007. ${ }^{9}$ Esta situação inviabiliza a terapêutica empírica, em ambulatório, para as infeções causadas por esta estirpe microbiana.

O Proteus mirabilis representava apenas $7 \%$ do total de isolados mas, destes, $21,6 \%$ foram causa de ITU no grupo etário < 16 anos. Esta bactéria apresenta uma baixa percentagem de sensibilidade às quinolonas (Ciprofloxacina $65,4 \%$ e Levofloxacina $75 \%$ ), pelo que não devem ser opção de tratamento de primeira linha. Apenas apresenta elevada sensibilidade ao Imipenem $(99,5 \%)$ e Amicacina $(95,7 \%)$, que não se encontram disponíveis para uso na comunidade. O Proteus mirabilis é sensível à Ceftriaxona em $96,8 \%$ das amostras.

A Nitrofurantoína apresenta boa eficácia para a $E$. coli (96\%) e E. faecalis (96\%), facto que se pode ficar a dever ao seu desuso nos últimos anos. O facto de necessitar de tratamento prolongado, pelo menos sete dias, quatro vezes ao dia, associado à sua toxicidade, recomenda ponderação para uso na comunidade. ${ }^{7}$

A Amicacina apresenta sensibilidade elevada para os cinco principais gérmenes (E. coli, Klebsiella, Proteus, Pseudomonas e Morganella), que representam 90\% do total de amostras do nosso estudo.

As cefalosporinas de segunda geração, representadas pela Cefuroxima, apresentam eficácia inferior para $E$. coli $(86,1 \%)$ e Proteus mirabilis $(87,2 \%)$, em comparação com as de terceira geração (Ceftazidima e Ceftriaxona), que se situa acima de $90 \%$.

A norma de orientação clinica $15 / 2011^{12}$ recomenda, no tratamento da cistite aguda não complicada, a Nitrofurantoína, Fosfomicina ou Amoxicilina-Ácido Clavulânico. Os resultados do presente estudo reforçam estas orientações 
terapêuticas no que respeita à Nitrofurantoína ou Fosfomicina, ambas com atividade para $E$. coli, a bactéria mais prevalente ( $66 \%$ das amostras). O mesmo não sucede com Amoxicilina-Ácido Clavulânico, que apresenta uma sensibilidade $84,8 \%$ e $87 \%$ nos grupos $<16$ e 16 a 35 anos, respetivamente, mas de apenas $73,5 \%$ no grupo $>75$ anos. No entanto, as limitações metodológicas inerentes ao presente estudo, que se baseou na análise de resultados de uroculturas, não tendo em conta a situação clinica dos doentes, não permitem firmar conclusões definitivas.

\section{CONCLUSÃO}

A terapêutica empírica das ITU é uma recomendação consensual, ${ }^{7-12}$ no entanto requer 0 conhecimento da prevalência das estirpes microbianas, bem como da sua sensibilidade aos antibióticos.

As estirpes bacterianas mais frequentes nas ITU da comunidade são a Escherichia coli $(65,9 \%)$, seguida da Klebsiella pneumoniae (12\%) e do Proteus mirabilis (7\%).

Em todos os grupos etários, as estirpes de Escherichia coli apresentaram sensibilidade sempre superior a $93 \%$ à Fosfomicina e $96 \%$ à Nitrofurantoína, estando recomendada esta terapêutica para a cistite aguda não complicada na mulher. No entanto, o grupo etário $>75$ anos, onde a prevalência deste patogéneo é de apenas $55,4 \%$, deve merecer especial cuidado.

A Amoxicilina-Ácido Clavulânico, sendo menos eficaz para a $E$. coli $(81,1 \%)$, não tem vantagens em relação à

\section{REFERÊNCIAS}

1. ECDC. Antimicrobial resistance surveillance in Europe. Sweden; 2012. [consultado 2014 Mar 02]. Disponível em: http://ecdc.europa.eu/en/ publications/Publications/antimicrobial-resistance-surveillance-europe-2012.pdf.

2. World Health Organization. Global strategy for containment of antimicrobial resistance. Geneve: WHO; 2001.

3. Goossens H, Ferech M, Vander Stichele R, Elseviers M. Outpatient antibiotic use in Europe and association with resistance: a cross-national database study. Lancet. 2005;365:579-87.

4. World Health Organization. Collaborating Centre for Drug Statistics Methodology. Guidelines for ATC classification and DDD assignment 2014. Oslo; 2013. [consultado 2014 Mar 05]. Disponível em: http://www. whocc.no/atc_ddd_publications/guidelines/.

5. Ramalhinho I, Ribeirinho M, Vieira I, Cabrita J. A evolução do consumo de antibióticos em ambulatório em Portugal continental 2000-2009. Acta Med Port. 2012;25:20-8.

6. Costa MC, Pereira PM, Bolotinha C, Ferreira A, Cardoso R, Monteiro C, et al. Frequência e susceptibilidade bacteriana em infecções urinárias: dados de um laboratório de Lisboa. Parte II. Rev Lusófona Ciên Tecnol Saúde. 2009;6:87-103.

7. Longo D, Fauci A, Dennis K, Hauser S, Jameson J, Loscalzo J, editors. Harrison's principles of internal medicine. $8^{\text {th }}$ ed. London: McGraw-Hill Professional; 2011.

8. Martins F, Vitorino J, Abreu A. Avaliação do perfil de susceptibilidade
Fosfomicina.

As estirpes de E. coli apresentam sensibilidade para as quinolonas de $78 \%$, inferior à Fosfomicina e Nitrofurantoína.

Salienta-se, ainda, que tanto a Nitrofurantoína como a Fosfomicina não têm penetração parenquimatosa, pelo que não são apropriadas ao tratamento de infeções altas (pielonefrites) ou infeções prostáticas.

Recomenda-se a continuação de estudos semelhantes ao agora realizado, de forma a acompanhar a evolução do perfil de sensibilidade dos microrganismos e a otimizar a terapêutica empírica das ITU.

\section{AGRADECIMENTOS}

Os autores agradecem a Maria Beatriz Santos e aos Laboratórios Beatriz Godinho, a Cristina Cruz e ao Laboratório Susana Rosas e a Marisa Lázaro e ao Laboratório Torres, pela disponibilização dos resultados das uroculturas.

A Gina Marrão pela consultadoria técnica.

\section{CONFLITOS DE INTERESSE}

Os autores declaram não haver conflito de interesses na realização da presente investigação.

\section{FONTES DE FINANCIAMENTO}

Este trabalho não recebeu qualquer contribuição e subsídio ou bolsa.

aos antimicrobianos de microrganismos isolados em urinas na região do Vale do Sousa e Tâmega. Acta Med Port. 2010;23:641-6.

9. Correia C, Costa E, Peres A, Alves M, Pombo G, Estevinho L. Etiologia das infecções do tracto urinário e sua susceptibilidade aos antimicrobianos. Acta Med Port. 2007;20:543-50.

10. Linhares, I, Raposo, T, Rodrigues, A, Almeida, A. Frequency and antimicrobial resistance patterns of bacteria implicated in community urinary tract infections: a ten-year surveillance study (2000-2009). BMC Infect Dis. 2013;13:1-14.

11. Gupta K, Hooton TM, Roberts PL, Stamm WE. Patient-initiated treatment of uncomplicated recurrent urinary tract infections in young women. Ann Intern Med. 2001;135:9-16.

12. Direcção Geral da Saúde. Terapêutica de infeções do aparelho urinário (comunidade). Departamento da Qualidade na Saúde. 2011(Norma 15/2011). Lisboa: DGS; 2011.

13. Baerheim A. Empirical treatment of uncomplicated cystitis. BMJ. 2001;323:1197-8.

14. Clinical and Laboratory Standards Institute. Performance standards for antimicrobial susceptibility testing: Nineteenth Informational Supplement M100-S19. Wayne: CLSI; 2009.

15. Kahlmeter G, Poulsen HO. Antimicrobial susceptibility of Escherichia coli from community-acquired urinary tract infections in Europe: The ECO.SENS study revisited. Int J Antimicrob Agents. 2012;39:45-51. 


\section{Avaliação do Perfil de Sensibilidade aos Antibióticos na Infeção Urinária da Comunidade}

Acta Med Port 2014:27:737-742

Publicado pela Acta Médica Portuguesa, a Revista Científica da Ordem dos Médicos

Av. Almirante Gago Coutinho, 151

1749-084 Lisboa, Portugal.

Tel: +351218428215

E-mail: submissao@actamedicaportuguesa.com

www.actamedicaportuguesa.com

ISSN:0870-399X | e-ISSN: 1646-0758

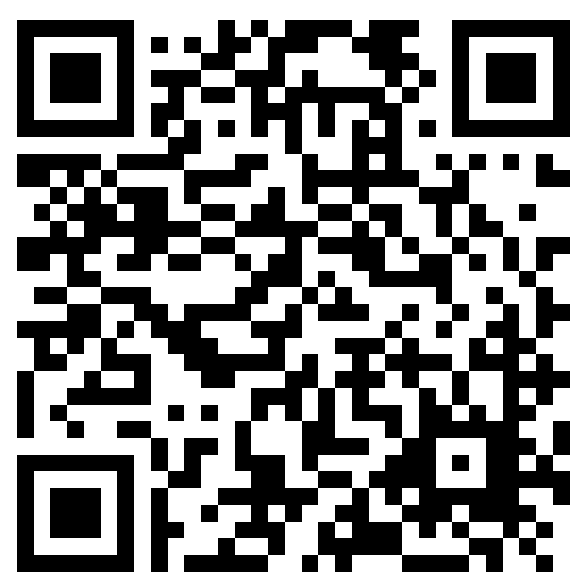

